\title{
Methanothermobacter thermautotrophicus modulates its membrane lipids in response to hydrogen and nutrient availability
}

\section{Marcos Y. Yoshinaga ${ }^{1 *}$, Emma J. Gagen ${ }^{2 \dagger \neq}$, Lars Wörmer ${ }^{1 \neq}$, Nadine K. Broda $^{1}$, Travis B. Meador ${ }^{1}$, Jenny Wendt ${ }^{1}$, Michael Thomm ${ }^{2}$ and Kai-Uwe Hinrichs ${ }^{1}$}

' Organic Geochemistry Group, MARUM Center for Marine Environmental Sciences, University of Bremen, Bremen, Germany

${ }^{2}$ Department of Microbiology and Archaea Center, University of Regensburg, Regensburg, Germany

\section{Edited by:}

Mark Alexander Lever, ETH Zürich,

Switzerland

\section{Reviewed by:}

Brian P. Hedlund, University of Nevada Las Vegas, USA

James F. Holden, University of Massachusetts Amherst, USA

\section{*Correspondence:}

Marcos Y. Yoshinaga, Organic Geochemistry Group, MARUM Center for Marine Environmental Sciences, University of Bremen, Leobener Straße, Bremen 28359, Germany e-mail:marcosyukio@gmail.com

\section{${ }^{\dagger}$ Present address:}

Emma J. Gagen, School of Earth

Queensland, Saint Lucia, OLD,

Australia

${ }^{\ddagger}$ These authors have contributed

equally to this work.
Sciences, The University of

\begin{abstract}
Methanothermobacter thermautotrophicus strain $\Delta \mathrm{H}$ is a model hydrogenotrophic methanogen, for which extensive biochemical information, including the complete genome sequence, is available. Nevertheless, at the cell membrane lipid level, little is known about the responses of this archaeon to environmental stimuli. In this study, the lipid composition of $M$. thermautotrophicus was characterized to verify how this archaeon modulates its cell membrane components during growth phases and in response to hydrogen depletion and nutrient limitation (potassium and phosphate). As opposed to the higher abundance of phospholipids in the stationary phase of control experiments, cell membranes under nutrient, and energy stress were dominated by glycolipids that likely provided a more effective barrier against ion leakage. We also identified particular lipid regulatory mechanisms in $M$. thermautotrophicus, which included the accumulation of polyprenols under hydrogen-limited conditions and an increased content of sodiated adducts of lipids in nutrient-limited cells. These findings suggest that $M$. thermautotrophicus intensely modulates its cell membrane lipid composition to cope with energy and nutrient availability in dynamic environments.
\end{abstract}

\section{Keywords: archaea, stress response, polar lipids, diether, tetraether}

\section{INTRODUCTION}

Analysis of intact polar lipids (IPL) - membrane-associated lipids such as phospholipids and glycolipids - is one strategy for investigating microbial populations in culture and natural systems (e.g., Sturt et al., 2004), and is being presently applied to understand archaea in natural ecosystems (e.g., Biddle et al., 2006; Lipp et al., 2008; Rossel et al., 2011; Schubotz et al., 2011, 2013). Although the analysis of individual compounds by NMR is mandatory for strict structural identification, advances in IPL detection by high-performance liquid chromatography coupled to mass spectrometry (HPLC-MS) have revealed an unprecedented variety of archaeal lipids (Yoshinaga et al., 2011; Liu et al., 2012; Becker et al., 2013; Wörmer etal., 2013; Zhu et al., 2013, 2014). This structural diversity of IPL might reflect both the staggering diversity of archaea in nature and mechanisms of archaeal cell membrane adaptation in response to environmentally relevant conditions (e.g., energy and nutrient limitation).

It is well known that bacteria modify their membrane IPL composition in response to growth and environmental conditions (e.g., Zhang and Rock, 2008; Zavaleta-Pastor et al., 2010), however, there is little information on how and whether such adaptation occurs in archaea. To date, controlled experiments to observe changes in archaeal lipids or test hypotheses about membrane adaptations in archaea have only been reported for the effect of temperature, growth stage and $\mathrm{pH}$ (inferred from optimum $\mathrm{pH}$ of a range of organisms) for a handful of archaea (e.g., Kramer and Sauer, 1991; Uda et al., 2004; Lai et al., 2008; Matsuno et al., 2009; Boyd et al., 2011). For instance, the number of cyclopentane rings in tetraether moieties of thermophilic archaea varies with growth temperature, reflecting an adaptation to adjust their membrane fluidity (Uda et al., 2001; Gliozzi et al., 2002).

Even fewer studies have investigated these changes at the IPL level (Nicolaus etal., 1989; Morii and Koga, 1993; Uda etal., 2001; Shimada et al., 2008; Elling et al., 2014; Meador et al., 2014). Increasing amounts of glycolipids relative to phospholipids in Thermoplasma acidophilum were demonstrated to decrease proton permeability (Shimada et al., 2008). More recently, cells of Thermococcus kodakarensis were shown to accumulate intracellular phosphorous in IPL, when subject to phosphate-limited conditions (Meador et al., 2014). Here, we sought to expand on these findings using controlled conditions and M. thermautotrophicus as a model organism. M. thermautotrophicus is a hydrogenotrophic methanogen from anaerobic environments and represents perhaps the most studied archaeon among the diverse groups of methanogens.

Previous investigations of $M$. thermautotrophicus focused on lipid changes during growth stages have led to contradictory results. For example a decrease (Kramer and Sauer, 1991) or an increase (Morii and Koga, 1993) in the relative abundance of tetraether lipids has been observed for cells transitioning from 
exponential growth to stationary phase. In contrast to these studies, which quantified the lipid classes after chemical hydrolysis, here we performed a direct quantification of IPL during growth stages by HPLC-MS (Wörmer et al., 2013). Moreover, we examined whether $M$. thermautotrophicus adapts its membrane lipid composition in response to: (1) energy limitation $\left(\mathrm{H}_{2}\right)$ and $(2)$ nutrient limitation (potassium and phosphate). Hydrogen and nutrient availability have been shown to significantly impact the cell wall and membrane components of M. thermautotrophicus both at the gene expression (e.g., Kato et al., 2008) and the molecular levels [e.g., cyclic 2,3-diphosphoglycerate (cDPG), Krueger et al., 1986; cell wall thickness, Nakamura et al., 2006]. This study represents the first attempt to investigate how $M$. thermautotrophicus modulates its IPL composition in response to environmentally relevant conditions that affect its growth.

\section{MATERIALS AND METHODS CULTIVATION CONDITIONS AND SAMPLING}

Methanothermobacter thermautotrophicus $\Delta H$ (DSM 1053) was grown at $65^{\circ} \mathrm{C}$ in $65 \mathrm{~L}$ bioreactors containing $50 \mathrm{~L}$ liquid medium. Standard medium was prepared anaerobically and contained per liter: $0.45 \mathrm{~g} \mathrm{NaCl}, 5 \mathrm{~g} \mathrm{NaHCO}_{3}, 0.1 \mathrm{~g} \mathrm{MgSO}_{4} .7 \mathrm{H}_{2} \mathrm{O}, 0.225 \mathrm{~g}$ $\mathrm{KH}_{2} \mathrm{PO}_{4}, 0.3 \mathrm{~g} \mathrm{~K}_{2} \mathrm{HPO}_{4} .3 \mathrm{H}_{2} \mathrm{O}, 0.225 \mathrm{~g}\left(\mathrm{NH}_{4}\right)_{2} \mathrm{SO} 4,0.06 \mathrm{~g}$ $\mathrm{CaCl}_{2} .2 \mathrm{H}_{2} \mathrm{O}, 0.002 \mathrm{~g}\left(\mathrm{NH}_{4}\right)_{2} \mathrm{Ni}\left(\mathrm{SO}_{4}\right)_{2}, 0.002 \mathrm{~g} \mathrm{FeSO}_{4} .7 \mathrm{H}_{2} \mathrm{O}, 1 \mathrm{mg}$ resazurin, final concentrations of $1 \mathrm{x}$ Wolfe's vitamins and $1 \mathrm{x}$ Wolfe's minerals, modified as outlined by Gagen et al. (2013) and $0.3 \mathrm{~g} \mathrm{Na}_{2} \mathrm{~S} .3 \mathrm{H}_{2} \mathrm{O}$ and $1.5 \mathrm{~g}$ cysteine hydrochloride monohydrate, as reducing agents. The $\mathrm{pH}$ was set to 7.5 using $\mathrm{H}_{2} \mathrm{SO}_{4}$. In reactors, 2 bar $\mathrm{H}_{2}: \mathrm{CO}_{2}$ (80:20 vol:vol) was provided as the energy and carbon source and gassing at approximately $1.5 \mathrm{~L}$ $\min ^{-1}$ was started when the culture was between early- and mid-exponential phase. Further reducing agents were added to reactors and the gassing rate increased to approximately $2.5 \mathrm{~L}$ $\min ^{-1}$ when the culture reached late exponential phase. Under these growth conditions, maximum cell concentrations of $5 \times 10^{8}$ cells $\mathrm{ml}^{-1}$ were routinely achieved. Samples (2 L) were harvested from reactors at late-exponential phase (L-Exp), $3 \mathrm{~h}$ after reaching maximum cell concentration (early stationary phase, E-Stat) and then nine (mid, M-Stat) and $18 \mathrm{~h}$ later (late, L-Stat). Samples were harvested by centrifugation at $13,000 \mathrm{~g}, 30 \mathrm{~min} ., 4^{\circ} \mathrm{C}$. After cooling, the remaining $42 \mathrm{~L}$ of culture in the reactors were also harvested by continuous flow-through centrifugation (end harvest samples).

For hydrogen limitation experiments, the gas phase of the reactor was switched to $\mathrm{N}_{2}: \mathrm{CO}_{2}(80: 20)$ when the maximal cell concentration was almost reached (i.e., $3 \mathrm{~h}$ before collection of sample E-Stat) and samples were collected at the same time points as for standard conditions (L-Exp to L-Stat). As such, samples L-Exp did not experience hydrogen-limited conditions, and they should thus be comparable to the control samples at this growth phase. In the nutrient limitation experiments, 2 bar $\mathrm{H}_{2}: \mathrm{CO}_{2}(80: 20$ vol:vol) was provided to $M$. thermautotrophicus that was adapted to and grown on medium with only $20 \mu \mathrm{M}$ potassium and $10 \mu \mathrm{M}$ phosphate available (substantially reduced compared to control medium, which offered ca. 4.3 and $3.0 \mathrm{mM}$, respectively). Samples from nutrient-limited experiments were only collected at L-Exp, E-Stat, and L-Stat. Gassing and addition of further reducing agents were not required for nutrient-limited cultures as neither altered the final maximal cell concentrations of only $2 \times 10^{7}$ cells $\mathrm{ml}^{-1}$ achievable under these conditions. All experiments were performed in triplicate, and the different treatments are summarized in Table 1.

\section{LIPID EXTRACTION AND ANALYSIS}

Lipids were extracted according to Sturt et al. (2004) with slight modifications. In brief, samples were first lyophilized and weighed. Dry cell mass (0.02-0.25 g) was combined with pre-combusted sand ( $2 \mathrm{~g}$ ) and extracted four times. Samples were extracted by ultrasonication into a solvent mixture (v:v) of methanol $(\mathrm{MeOH})$, dichloromethane (DCM), and aqueous buffer (2:1:0.8). A phosphate buffer ( $\left.8.7 \mathrm{~g} \mathrm{~L}^{-1} \mathrm{KH}_{2} \mathrm{PO}_{4}, \mathrm{pH} 7.4\right)$ was used for the first two steps, and a trichloroacetic acid buffer $\left(50 \mathrm{~g} \mathrm{~L}^{-1}, \mathrm{pH} 2\right)$ for the final two steps. Supernatants were pooled in a separation funnel and DCM and water were added in order to allow optimal phase separation. After transferring the organic phase, the aqueous phase was extracted three more times with DCM. Pooled organic layers were then washed three times with deionized milliQ water. The final extract was gently evaporated under $\mathrm{N}_{2}$ flow and stored at $-20^{\circ} \mathrm{C}$.

Chromatographic separation was achieved on a Waters Acquity BEH $\mathrm{C}_{18}$ column (Wörmer et al., 2013) with a Dionex Ultimate 3000RS UHPLC coupled to a maXis quadrupole time-of-flight

\section{Table 1 | Summary of experimental conditions (control, hydrogen- and nutrient-limited treatments) and respective cell concentrations ( $\times 10^{8}$ cells $\mathrm{ml}^{-1}$, in parenthesis the SD) of Methanothermobacter thermautotrophicus at: late exponential phase (L-Exp), early, mid, and late stationary phases (E-, M-, and L-Stat).}

\begin{tabular}{|c|c|c|c|c|c|c|c|c|c|c|c|}
\hline & \multicolumn{4}{|c|}{ Control } & \multicolumn{4}{|c|}{ Hydrogen-limited } & \multicolumn{3}{|c|}{ Nutrient-limited } \\
\hline \multirow[t]{2}{*}{ Headspace } & \multicolumn{4}{|c|}{$80: 20\left(\mathrm{H}_{2}: \mathrm{CO}_{2}\right.$ vol:vol) } & \multirow{2}{*}{\multicolumn{4}{|c|}{$\begin{array}{c}80: 20\left(\mathrm{H}_{2}: \mathrm{CO}_{2}\right) \text { until L-Exp and } \\
80: 20\left(\mathrm{~N}_{2}: \mathrm{CO}_{2}\right) 3 \mathrm{~h} \text { prior to E-Stat }\end{array}$}} & \multicolumn{3}{|c|}{$80: 20\left(\mathrm{H}_{2}: \mathrm{CO}_{2}\right.$ vol:vol) } \\
\hline & & & & & & & & & & & \\
\hline \multirow[t]{2}{*}{ Nutrients } & \multicolumn{4}{|c|}{4.3 and $3.0 \mathrm{mM}$} & \multicolumn{4}{|c|}{4.3 and $3.0 \mathrm{mM}$} & \multicolumn{3}{|c|}{20 and $10 \mu \mathrm{M}$} \\
\hline & L-Exp & E-Stat & M-Stat & L-Stat & L-Exp & E-Stat & M-Stat & L-Stat & L-Exp & E-Stat & L-Stat \\
\hline Cell & 1.0 & 6.9 & 5.7 & 6.0 & 1.6 & 5.0 & 5.1 & 4.9 & 0.1 & 0.2 & 0.2 \\
\hline concentrations & $(0.8)$ & $(1.1)$ & $(0.7)$ & $(0.8)$ & $(0.3)$ & $(0.2)$ & $(0.2)$ & $(0.1)$ & $(0.09)$ & $(0.01)$ & $(0.01)$ \\
\hline
\end{tabular}

Headspace gas atmosphere (vol:vol) and concentrations of potassium and phosphate, respectively. 
mass spectrometer (Q ToF-MS, Bruker Daltonics, Bremen, Germany) equipped with an ESI source. Detection of lipids was performed in positive ionization mode while scanning a mass-tocharge $(\mathrm{m} / \mathrm{z})$ range from 150 to $2,000 . \mathrm{MS}^{2}$ scans were obtained in data-dependent mode, for each MS full scan up to three $\mathrm{MS}^{2}$ experiments, targeting the most abundant ions, were performed. Active exclusion limits the times a given ion is selected for fragmentation (three times every $0.5 \mathrm{~min}$ ) and thus allowed to also obtain $\mathrm{MS}^{2}$ data of less abundant ions. Lipid identification was achieved by monitoring exact masses of possible parent ions (present as either $\mathrm{H}^{+}, \mathrm{NH}_{4}{ }^{+}$, or $\mathrm{Na}^{+}$adducts) in combination with characteristic fragmentation patterns as outlined by Yoshinaga et al. (2011) and supported by compound identities revealed in previous studies (Kramer et al., 1987; Nishihara et al., 1987, 1989; Morii and Koga, 1994).

Lipid quantification was achieved by comparison of parent ion responses relative to known amounts of an internal standard (1,2dihenarachidoyl-sn-glycero-3-phosphocholine, $\mathrm{C}_{21}$-PC, Avanti Lipids). Reported concentrations were corrected for response factors of commercially available standards (core archaeol, AR, and phosphoethanolamine archaeol, PE-AR, from Avanti Polar Lipids Inc., USA and phosphatidyl-glycerol-monoglycosyl glycerol-dibiphytanyl-glycerol-tetraether, PG-GDGT-G, from Matreya LLC, Pleasant Gap, PA, USA) and purified standards (core GDGT, G-GDGT, 2G-GDGT, G-AR, and 2G-AR) from Archaeoglobus fulgidus as described in Zhu et al. (2013). Among the tetraethers, all core GDGT and intact GDGT with more than one sugar and those with phosphate-bearing headgroups were quantified using the response factors of core GDGT, 2G-GDGT, and PG-GDGT$\mathrm{G}$, respectively. The abundance of intact AR with more than one sugar and phosphate-bearing headgroups were corrected, respectively, for the response factors of $2 \mathrm{G}-\mathrm{AR}$ and PE-AR standards. The unmodified and glycosylated polyprenols (with additional modifications thereof) were corrected by their response factors relative to core $\mathrm{AR}$ and $\mathrm{G}-\mathrm{AR}$, respectively.

\section{CELLULAR CARBON}

Aliquots of lyophilized cell pellets $(0.5-2 \mathrm{mg})$ were subjected to hydrochloric acid $(\mathrm{HCl})$ vapor overnight to remove inorganic carbon. Mass percentage of $\mathrm{C}$ was determined using a ThermoFinnigan Flash Elemental Analyzer 2000 (Bremen, Germany). In order to compare the distinct treatments, we applied the carbon to lipid ratio (e.g., Lipp et al., 2008). Although the cellular amounts of lipids and total carbon can vary widely, the ratio of cellular carbon and cell membrane lipids does not fluctuate widely with cell volume ( ratio $=11-15$, cf., Simon and Azam, 1989).

\section{STATISTICAL ANALYSES}

The Simpson diversity index $(D)$, typically used to compare species diversity, was applied to the data to estimate lipid diversity (cf., Meador et al., 2014). The $D$ values range from 0 to 1 , such that a value approaching 1 represents high lipid diversity and values close to 0 represent no diversity.

Principal component analysis (PCA) was performed on the raw MS chromatograms with Bruker Profile Analysis 2.0 in a $m / z$ range from 600 to 2000 and between 10 and 25 min., thus including all lipids. Rectangular bucketing was established with dimensions of $1 \mathrm{~min}$ and $1 \mathrm{~m} / \mathrm{z}$ units and data were normalized to the sum of buckets in each analysis. Samples were grouped according to treatments. In order to maximize comparability among samples for PCA, one replicate sample from hydrogen-limited experiments that was measured 2 weeks later than the others was excluded. Since main differences are expected to occur during the stationary phase, we also chose to exclude all L-Exp samples and include end-harvest samples of control and hydrogen-limited treatments. Because the latter are comparable to the L-Stat samples, they were not shown in IPL characterization.

\section{RESULTS AND DISCUSSION LIPID COMPOSITION OF M. thermautotrophicus}

Early investigations by thin layer chromatography coupled to fast atom bombardment MS or NMR have confirmed the identity of 23 different IPL in M. thermautotrophicus (Kramer et al., 1987; Nishihara et al., 1987, 1989). Based on HPLC-MS, our data show that $M$. thermautotrophicus $\Delta H$ (DSM 1053) membrane structure consists of ca. 65 different IPL, including diethers and tetraethers attached to glycosyl, phosphatidyl, and glycophosphatidyl headgroups (Figure 1). Nonetheless, with the exception of a relatively minor content of phosphatidyl-inositol (PI) AR, the major IPL reported in earlier studies (Nishihara et al., 1989; Morii and Koga, 1993) also represented dominant classes in the control samples in this study (Figure 2A).

Several IPL are reported here for the first time (Supplementary Tables S1 and S2; Supplementary Figure S1). To our knowledge, the $\mathrm{C}_{15}-\mathrm{C}_{20}$ archaeol (short-AR) has never been described, and this novel archaeal core lipid is exclusively bound to phosphatidylethanolamine (PE) and phosphatidyl-serine (PS). The short-AR derivatives are likely synthesized via farnesyl diphosphate, since $M$. thermautotrophicus possesses genes encoding for short chain isoprenyl diphosphate synthase (Chen and Poulter, 1994). Although D-glucose has been reported as the sole sugar moiety in total lipid extracts from $M$. thermautotrophicus previously (Nishihara et al., 1987), the deoxy-glycosidic headgroup identified in our study appeared both in $\mathrm{C}_{20}-\mathrm{C}_{20}$ archaeol (AR) and glycerol-dibiphytanyl-glycerol-tetraethers (GDGT). Moreover, while sugar headgroups in $M$. thermautotrophicus have been reported exclusively as diglycosyl moieties (Morii et al., 2007), we also found the monoglycosyl derivatives of AR and GDGT. Novel glycosidic headgroups of AR were also detected, and included the tentatively identified phosphatidyl- $N$-acetylglycosaminyl, acetyl-, and/or glycerol-glycosyl moieties (Supplementary Figure S1).

While GDGT have been previously detected in M. thermautotrophicus with additional methylation in dibiphytanyl moieties (Knappy et al., 2009), our study observed for the first time that these methylated GDGT, with up to three methylations, were prevalent over acyclic $\mathrm{C}_{40}-\mathrm{C}_{40}$ GDGT (caldarchaeol) not only as core lipids, but also as IPL (Supplementary Table S1). Formation of tetraethers in $M$. thermautotrophicus is hypothesized to occur via head-to-head condensation of two diether lipids (e.g., Nishihara et al., 1989; Morii and Koga, 1994). Consistent with this model, the detection of a novel intact methylated $\mathrm{C}_{21}-\mathrm{C}_{20}$ AR (Supplementary Table S1, Supplementary Figure S1) suggests that the addition of a methyl group may occur in phytanyl chains, i.e., prior to the head-to-head condensation. Methylated GDGT seem to be a 
typical membrane lipid feature among thermophilic archaea, as they have been detected in both culture (Methanopyrus kandleri, Liu et al., 2012; Thermococcus kodakarensis, Meador et al., 2014) and environmental samples (Reeves et al., 2014).

\section{LIPID COMPOSITION IN RELATION TO GROWTH PHASE - CONTROL EXPERIMENTS}

A higher proportion of diethers relative to tetraethers ( $87 \pm 5 \%$, $n=33$ samples) was observed in all treatments and throughout the cell growth phases of $M$. thermautotrophicus (Figure 1). These results contrast with the drastic shifts either to higher proportion of diethers (Kramer and Sauer, 1991) or tetraethers (Morii and Koga, 1993) during the stationary phase of M. thermautotrophicus. The most likely reason for this noticeable discrepancy is that the previous studies employed distinct methods other than HPLCMS for quantification of the diether/tetraether ratios (Iatroscan, which utilizes a flame ionization detector and ether cleavage and analysis of hydrocarbon chain by gas liquid chromatography, respectively). Nevertheless, in contrast to earlier reports of substantial shifts in core lipid composition but relatively constant headgroup composition throughout the growth phases, we observed striking differences in headgroup composition of both diether and tetraether IPL between different growth phases from M. thermautotrophicus control samples.

The most prominent feature observed within the control samples was the drastic decrease in proportions of glycosidic AR relative to total IPL during the transition from exponential growth to late stationary phases (Figure 1A). This change in IPL composition was associated with higher contributions of PS- and PE-AR to total diether lipids (Figure 2A), including minor AR attached to PI and phosphatidic acid (PA) headgroups. Although similar contributions of GDGT to total IPL were observed throughout the growth phases, our results revealed an increase in glycophosphatidyl headgroups, mainly G-PE and G-PI, and to a lesser extent G-PS. Reduced contributions of glycosidic AR toward the latestationary phase were accompanied by relatively lower proportions of G-GDGT and headgroup-free core lipids (Supplementary Table S1).

This systematic substitution of glycosyl by phosphatidyl headgroups in diethers and tetraethers IPL classes is consistent with the putative hypothesis of GDGT biosynthesis via head-to-head condensation in archaea (e.g., M. thermautotrophicus, Nishihara et al., 1989; T. acidophilum, Nemoto et al., 2003). That is, an increase in phosphate-based AR was reflected in higher proportions of glycophosphatidyl GDGT in stationary growth phases (Figure 2A). The factors controlling IPL modification during growth phases under optimum conditions are still unknown, but could be related to the IPL orientation in the membrane bilayer (Morii and Koga, 1994) as will be discussed below in concert with low energy/nutrient treatments.

\section{LIPID COMPOSITION IN RESPONSE TO GROWTH-LIMITING CONDITIONS}

In order to investigate the membrane lipid composition responses of $M$. thermautotrophicus to growth-limiting effects, we first examined the conditions under which growth was suppressed but not stopped (Table 1). Although slightly lower cell concentrations were
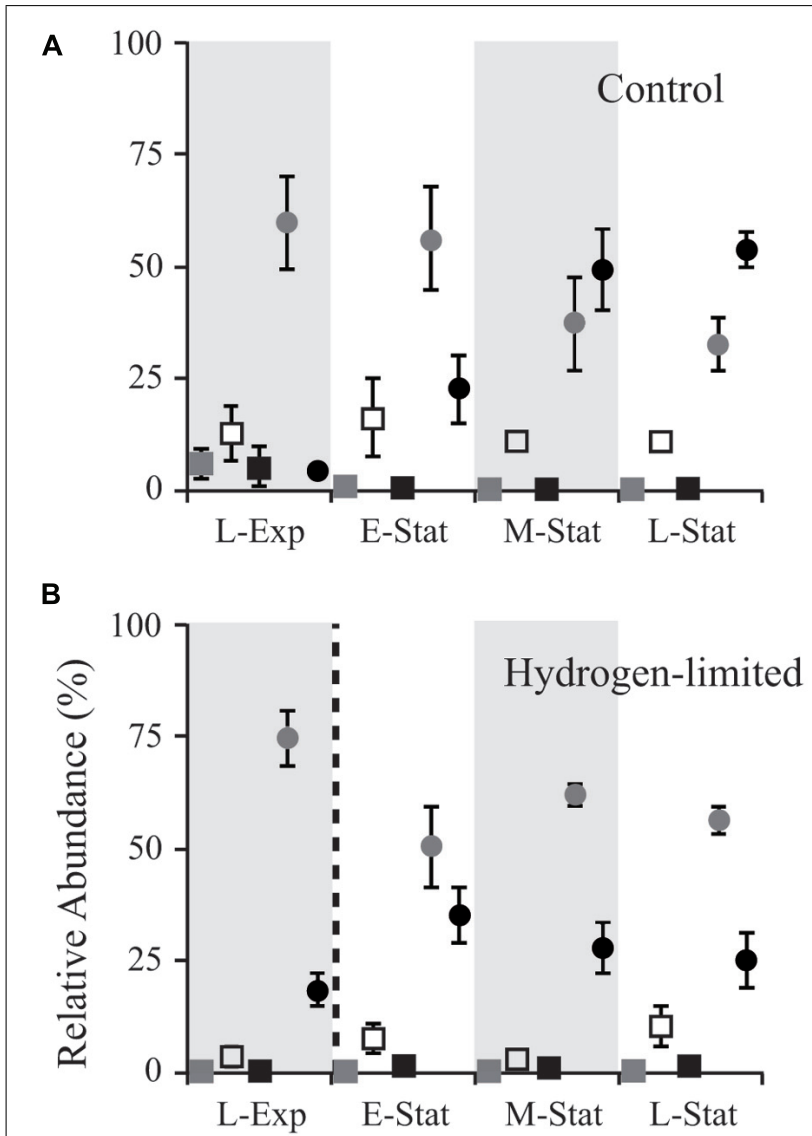

C
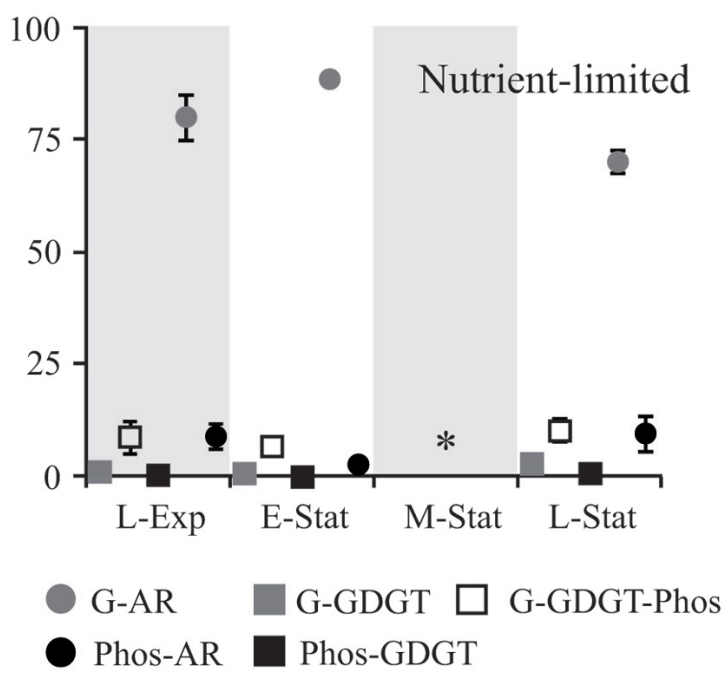

FIGURE 1 | Abundance of IPL relative to total lipids (including both core and IPL) during growth of Methanothermobacter thermautotrophicus under control (A), hydrogen limiting (B), and nutrient limiting (C) conditions at: late exponential phase (L-Exp), early, mid and late stationary phases (E-, M-, and L-Stat). The dashed line in (B) denotes the change in headspace from $80: 20 \mathrm{H}_{2}: \mathrm{CO}_{2}$ to $\mathrm{N}_{2}: \mathrm{CO}_{2}$ (vol:vol) $3 \mathrm{~h}$ before sampling $\mathrm{E}-\mathrm{Stat}$ in hydrogen-limited experiments. Star symbol $\left({ }^{*}\right)$ in $(\mathbf{C})$ represents no data. The experiments were conducted in triplicate and error bars represent standard error of the mean. G, glycosidic; Phos, phosphatidic; AR, archaeols/diethers; GDGT, tetraethers. 


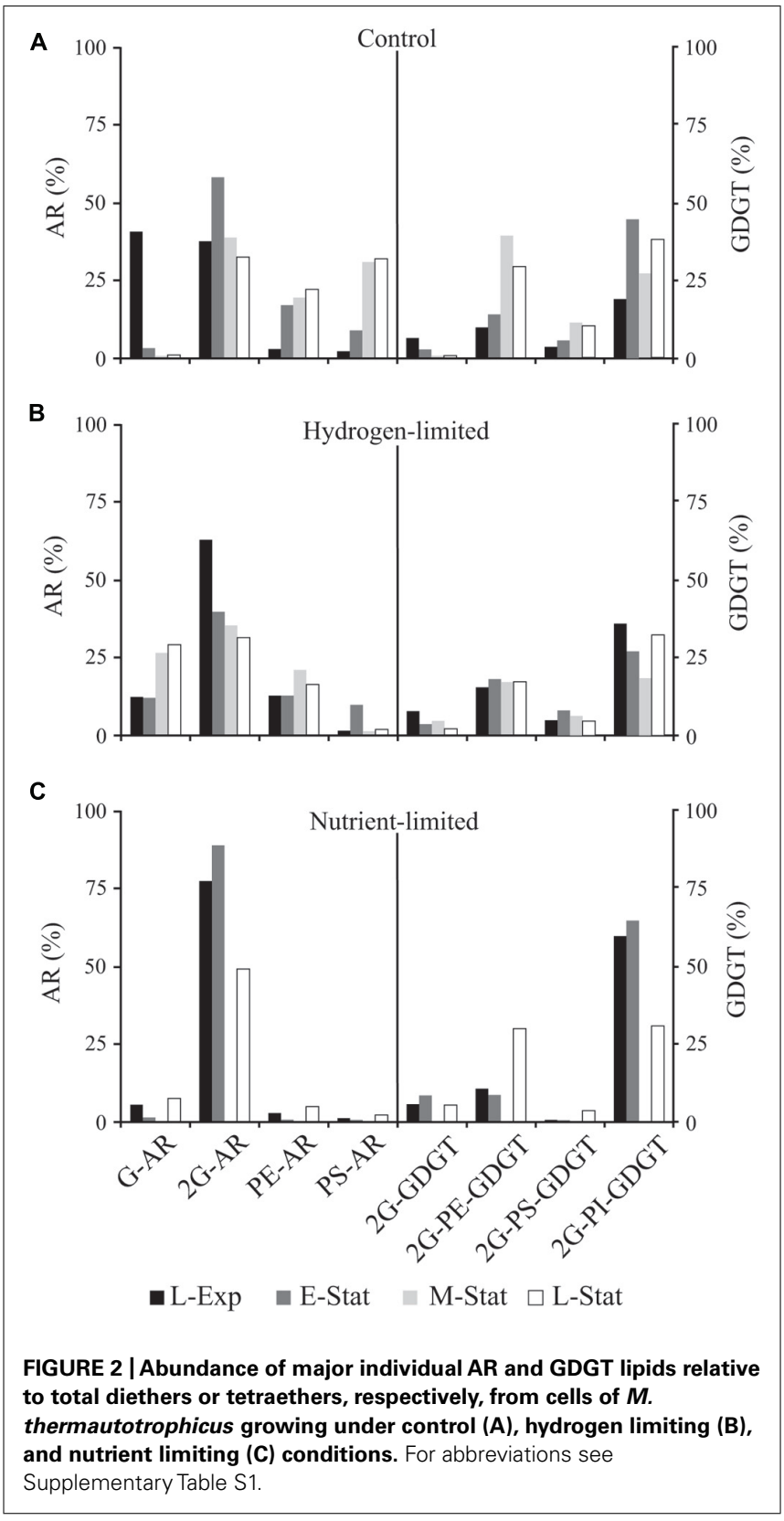

observed during the transition from E-Stat to L-Stat in hydrogen limitation treatments, they were in the same order of magnitude compared to control. Maximum cell concentrations for nutrientlimited experiments were 20-times lower than those reached under control conditions, reflecting poor culture growth imposed by phosphate- and potassium-limiting conditions.

The drastic exchange of glycosyl by phosphatidyl AR observed during growth phases in control experiments was not observed in hydrogen- and nutrient-limited treatments (Figures 1 and 2). Rather, the gradual increase in phosphatidyl AR from L-Exp to E-Stat in hydrogen limitation experiments was interrupted soon after the gas exchange from $\mathrm{H}_{2}: \mathrm{CO}_{2}$ to $\mathrm{N}_{2}: \mathrm{CO}_{2}$, leading to a rapid decrease in the contribution of these lipids to the total IPL pool (Figure 1B). In nutrient limitation experiments, glycosidic AR represented the majority of IPL in M. thermautotrophicus and no major changes were observed throughout the growth stages.

Differences among treatments were also evidenced by the Simpson diversity index $(D)$ and carbon-to-lipid ratio. While similar $D$ values were obtained for control and hydrogen-limited treatments, the diversity of lipids was comparatively higher in nutrient limitation experiments regardless of the growth phase (Supplementary Figure S2). Cellular carbon-to-lipid ratios observed in control and hydrogen-limited treatments were highly variable (from 14 to 44), substantially higher than the values of 11 to 15 reported by Simon and Azam (1989) for planktonic bacteria. These ratios were relatively higher in nutrient-limited treatments, especially when reaching the E-Stat phase (56-81, Supplementary Figure S2).

To further assess IPL variability, changes in the relative abundance of individual compounds were evaluated by PCA, in which the first two principal components $\mathrm{PC} 1$ and $\mathrm{PC} 2$ explained $62 \%$ of the observed variance (Figure 3). Nutrient-limited samples clustered close to each other, displaying negative values in $\mathrm{PC} 1$ that were associated with 2G-AR with both ammonium and sodiated adducts. While low amounts of sodiated relative to ammonium adducts are produced during ESI ionization (e.g., Zhu etal., 2013), in this study we detected an extraordinarily high abundance of sodiated adducts in nutrient-limited samples (Supplementary Figure S3), suggesting that their occurrence reflects a biological response rather than an analytical phenomenon linked to the ionization conditions in the mass spectrometer. Because compelling evidence exists for the occurrence of 2G-AR naturally bound to $\mathrm{Na}^{+}$and $\mathrm{K}^{+}$in M. thermautotrophicus (Kramer et al., 1988), we investigated whether other forms of sodiated adducts were also present. Interestingly, sodiated forms of both glyco- and phospholipids, including the most abundant IPL (i.e., G-AR, PS-AR, and PE-AR), showed negative values in PC1 and did not cluster with the $\mathrm{H}^{+}$or $\mathrm{NH}_{4}{ }^{+}$counterparts (Figure 3), as would be expected if the different adducts were formed from the same compound during ESI ionization.

Control and hydrogen-limited samples generally displayed positive values in $\mathrm{PC}$, which were correlated with diagnostic IPL including the major diether phospholipids of M. thermautotrophicus (i.e., PE-AR and PS-AR) and two compounds with parent ions of $\mathrm{m} / \mathrm{z} 792$ and 722 . Those latter compounds were identified as polyisoprenoidal alcohols or polyprenols, comprising 9-11 isoprene subunits (Supplementary Figure S4). While phosphate- or pyrophosphate-bound polyisoprenoids have been identified in eukaryotes, bacteria, and archaea (Swiezewska and Danikiewicz, 2005; Jones et al., 2009; Hartley and Imperiali, 2012), the polyprenols identified here did not possess phosphate (Supplementary Figure S4). Undecaprenyl monophosphate has been identified as the major sugar carrier for pseudomurein biosynthesis in M. thermautotrophicus (Hartmann and König, 1990). Although we cannot exclude a potential loss of monophosphate during TCA-based extraction (Lechner et al., 1985), phosphatefree polyprenols could play a distinct biochemical role in M. thermautotrophicus (e.g., membrane stability; Hartley and Imperiali, 2012).

Explaining 19\% of the averaged IPL composition, PC2 also revealed trends differentiating the three treatments (Figure 3 ). 


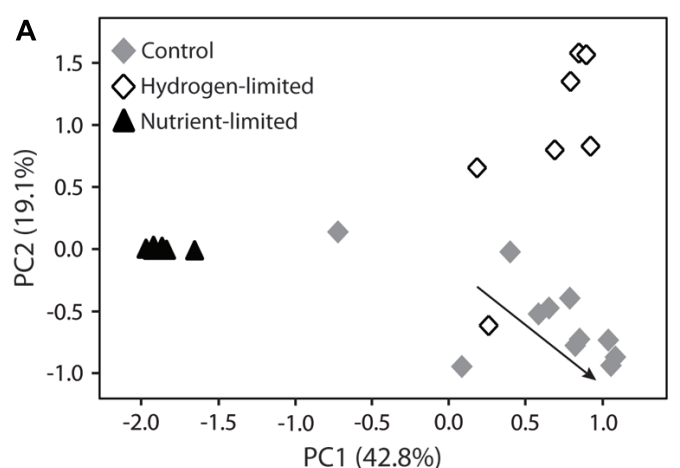

FIGURE 3 | Principal component analysis (PCA) of $M$. thermautotrophicus growing under control, hydrogen-limited and nutrient-limited conditions. Bi-plots of two main principal components, PC1 and PC2, displayed as (A) samples from distinct treatments and (B) lipid distribution. The arrow in (A) illustrates control samples transitioning from late exponential growth to stationary phase. $\left[\mathrm{Na}^{+}\right]$indicates IPL

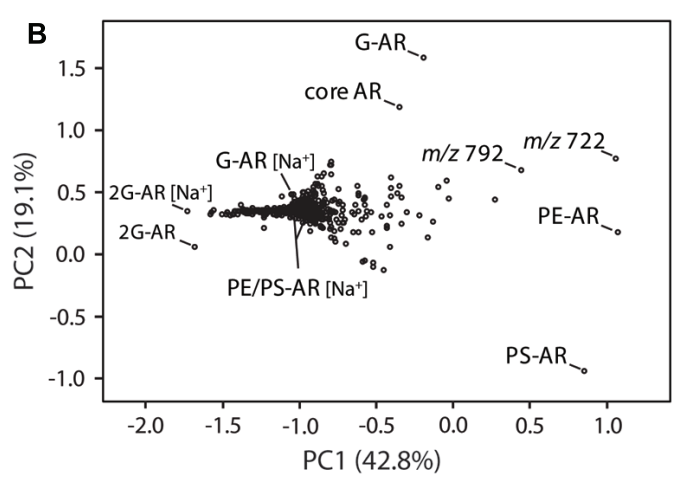

bound to sodium and masses $\mathrm{m} / \mathrm{z} 722$ and 792 represent the most abundant unmodified polyprenols (B), respectively, containing 10 and 11 isoprene units (see Supplementary Figure S4). For compounds abbreviations and detailed information on the PCA analysis please refer to Supplementary Table S1 and Section "Materials and Methods," respectively.
The majority of samples from the hydrogen-limited experiments exhibited positive values in PC2, which were associated with monoglycosidic (G-AR) and core AR. Nutrient-limited samples clustered near to the origin, while most samples from control experiments clustered with negative values in PC2, which were strongly related to PS-AR.

\section{POSSIBLE MECHANISMS INVOLVED IN IPL MODIFICATION DURING GROWTH STAGES AND HYDROGEN/NUTRIENT LIMITATION}

Morii and Koga (1994) found that the arrangement of IPL in the cell membrane of $M$. thermautotrophicus was asymmetrical and that most diglycosyl headgroups of both AR and GDGT as well as phosphoethanolamine bound to AR were located in the outer surface of the cell membrane. In contrast, the other phosphatidyl headgroups were found to face the cell interior, including serine and inositol headgroups of both AR and GDGT, and the ethanolamine from glycophosphatidyl GDGT. In our study, modifications in IPL were mostly related to the headgroup composition as similar ratios of tetraether relative to diether lipids were detected throughout the growth phases and among treatments. Therefore, positioning of IPL headgroups on the cell membrane of $M$. thermautotrophicus may be a critical response to energy and nutrient stress.

Shifts in IPL composition during growth stages in control experiments were larger than those observed in nutrient limitation treatments (Figures 1 and 2). This membrane lipid modification consisted of an increase in proportions of phosphatidyl relative to glycosyl headgroups of IPL toward the L-Stat, quite distinguishable from equivalent hydrogen-limited cells. One explanation for the accumulation of phosphatidyl IPL during the stationary phase is that these types of lipids have higher rates of lateral diffusion, i.e., higher permeability, than membranes made of glycolipids (Baba et al., 2001). The presence of more laterally mobile membranes could enhance rates of energy production at the expense of energy conservation (Valentine, 2007). M. thermautotrophicus may thus increase the proportion of glycolipids under energy and nutrient stress, decreasing the proton permeability of cell membranes.
A high proportion of glyco-relative to phospholipids was indeed observed in growth-limiting treatments. However, whereas $2 \mathrm{G}$-AR represented the majority of IPL in nutrient-limited experiments, increased abundances of G-AR and G-GDGT were observed toward the L-Stat in hydrogen-limited conditions (Figure 2; Supplementary Table S1). As opposed to bilayerforming diglycosidic headgroups, the substitution of phospho- by monoglycosidic headgroups under hydrogen limitation might be linked to their non-bilayer properties and associated lipid-protein interactions at the membrane level, similarly to observations in bacterial (Wikström et al., 2004) and photosynthetic cells (Hölzl and Dörmann, 2007). On the other hand, the reason for a relatively larger quantity of diglycosidic IPL in nutrient limitation treatments may be related to the formation of hydrogen-bond network among sugar headgroups (Hinz et al., 1991; Baba et al., 2001), similarly to T. acidophilum in response to low $\mathrm{pH}$ and high temperature (Shimada et al., 2008). By increasing the number of glycosyl headgroups per unit of IPL, M. thermautotrophicus may decrease membrane fluidity and protect cell membranes, particularly at the outer face, from chemically unstable conditions.

In comparison with the other treatments, M. thermautotrophicus cells under nutrient limitation were also characterized by a relatively lower importance of polyprenols and by the synthesis of IPL tightly bound to $\mathrm{Na}^{+}$(Figure 3 and Supplementary Figure S3). Under potassium limiting conditions, M. thermautotrophicus has been shown to accumulate intracellular $\mathrm{K}^{+}$, generating gradients as large as 50,000-fold between internal and external concentrations (Schönheit et al., 1984; Krueger et al., 1986). Rather than being driven by membrane potential or external osmotic pressure, this phenomenon could be related to the accumulation of the cyclic 2,3-diphosphoglycerate (cDPG), which bears a -3 charge at physiological $\mathrm{pH}$ and could function as a counter ion for $\mathrm{K}^{+}$accumulation (Krueger et al., 1986). cDPG represents a major carbon- and phosphorous-containing solute in M. thermautotrophicus (Seely and Fahrney, 1983; Evans et al., 1985) and due to its accumulation, phosphorous-limited cells exhibit a total phosphorus content comparable to that of 
cells from optimized batch cultures (Seely and Fahrney, 1984; Krueger et al., 1986). Since salt forms of lipids in Methanosarcina mazei have been demonstrated to add stability to the cells by influencing the permeability of membranes to retain low molecular weight compounds (Patel et al., 1999), it is conceivable to propose that IPL bound to $\mathrm{Na}^{+}$in $M$. thermautotrophicus are used to maintain essential intracellular concentrations of cDPG under nutrient-limited conditions. The accumulation of $\mathrm{CDPG}$ would also explain the high carbon-to-lipid ratios observed in early growth stages of these cells (Supplementary Figure S2). The substantially lower cell concentrations in nutrientlimited experiments compared to the other treatments could have been triggered by the lack of available phosphorus as an essential cellular component. Moreover, these lower cell concentrations could possibly reflect the increased energy demand on cells related to $\mathrm{K}^{+}$uptake and maintenance of $\mathrm{K}^{+}$concentration gradients (Schönheit et al., 1984; Krueger et al., 1986). The unique lipid profile exhibited by nutrient-limited cells can thus be considered a response of $M$. thermautotrophicus to chronic stress.

Although displaying similar cell concentrations, carbon-tolipid ratios and IPL diversity in comparison with control experiments, cells growing under hydrogen stress presented very distinct IPL composition as evidenced by PCA analysis, including an apparently high abundance of polyprenols. With the exception of nutrient limitation treatments, polyprenols were extremely abundant in all our samples, accounting for up to $40 \%$ of total lipids (Supplementary Table S1). While the function of phosphate-free polyprenols is still unclear, there exists significant evidence for an increase in fluidity and ion permeability of membranes, including changes in membrane conformation (e.g., Hartley and Imperiali, 2012). Under hydrogen limitation, it has been reported that $M$. thermautotrophicus increases its cell wall thickness (Nakamura et al., 2006) and upregulates genes related to polysaccharide biosynthesis (Kato et al., 2008). Given the importance of their phosphate-bearing counterparts as sugar carriers for pseudomureins synthesis in M. thermautotrophicus (Hartmann and König, 1990), the high abundance of polyprenols may alternatively reflect a link with the production of pseudomureins (Kandler and König, 1998), for the purpose of cell wall thickening in response to energy stress.

\section{CONCLUSION}

Although archaeal lipids have been studied for many years, innovative HPLC-MS methods have allowed the characterization of novel molecular structures in a single analytical run, which are useful to investigate detailed membrane lipid composition of archaea both in cultures and natural systems. In M. thermautotrophicus, methylated forms of GDGT predominate over caldarchaeol. Additionally, methylation of caldarchaeol represents a characteristic feature among thermophilic archaea and has implications for studying thermophilic lipids in environmental samples (e.g., hydrothermal systems) and in biotechnology (e.g., permeability of liposomes).

Methanobacterium thermautotrophicus responded similarly to growth under energy and nutrient limitation. That is, cell membranes under these growth-limiting conditions were dominated by glycolipids, which face the outer leaflet of the membrane bilayer, as opposed to the higher abundance of phospholipids in control experiments. While this major lipid shift could be attributed to regulatory mechanisms of cell membrane permeability in $M$. thermautotrophicus, the role of membrane lipids is much more diverse as they actively participate in various essential cellular processes. A headgroup substitution in IPL from growth-limited cells may implicate regulation of lipid-protein interactions, causing protein conformation changes, with crucial consequences for the balance between energy production and conservation.

In agreement with previously observed increases in cell wall thickness for energy-limited $M$. thermautotrophicus, specific lipid modifications under hydrogen depletion included the accumulation of polyprenols, which may play a role in the synthesis of pseudomureins. If connected to the increased proportion of glycolipids that provide a more effective barrier to ions, the reason for increasing cell wall thickness might be cellular regulation to decrease membrane permeability and leakage of ions in response to energy limiting conditions. These observations are in line with the varying $\mathrm{H}^{+} /$ATP or $\mathrm{Na}^{+} /$ATP stoichiometry, i.e., the protons translocated per ATP formed by $M$. thermautotrophicus according to the availability of energy (Poorter et al., 2003).

Despite exhibiting low contents of polyprenols and substantially lower cell concentrations in comparison with other treatments, $M$. thermautotrophicus cells under potassium and phosphate limitation were characterized by a surprisingly high content of salt forms of lipids. While the function of these lipids bound to $\mathrm{Na}^{+}$in $M$. thermautotrophicus is still uncertain, they may be related to the retention of $\mathrm{CDPG}$, which is essential to counterbalance the intracellular accumulation of $\mathrm{K}^{+}$under potassium limiting conditions. Collectively our findings suggest that M. thermautotrophicus intensely modulates its cell membrane lipid composition to cope with energy and nutrient availability in dynamic environments.

\section{ACKNOWLEDGMENTS}

Marcos Y. Yoshinaga, Emma J. Gagen, Lars Wörmer, and Travis B. Meador were supported by the European Research Council under the European Union's Seventh Framework Programme'Ideas' Specific Programme, ERC grant agreement No. 247153 (to Kai-Uwe Hinrichs). Marcos Y. Yoshinaga, Travis B. Meador, and Lars Wörmer were additionally funded by Deutsche Forschungsgemeinschaft through the Gottfried Wilhelm Leibniz Award to Kai-Uwe Hinrichs We are also grateful to Matthias Y. Kellermann, Florence Schubotz, Miriam Sollich, and Raymond C. Valentine for fruitful discussions.

\section{SUPPLEMENTARY MATERIAL}

The Supplementary Material for this article can be found online at: http://www.frontiersin.org/journal/10.3389/fmicb.2015.00005/ abstract

\section{REFERENCES}

Baba, T., Minamikawa, H., Hato, M., and Handa, T. (2001). Hydration and molecular motions in synthetic phytanyl-chained glycolipid vesicle membranes. Biophys. J. 81, 3377-3386. doi: 10.1016/S0006-3495(01)75970-X

Becker, K. W., Lipp, J. S., Zhu, C., Liu, X.-L., and Hinrichs, K.-U. (2013). An improved method for the analysis of archaeal and bacterial 
ether core lipids. Org. Geochem. 61, 34-44. doi: 10.1016/j.orggeochem.2013. 05.007

Biddle, J. F., Lipp, J. S., Lever, M. A., Lloyd, K. G., Sørensen, K. B., Anderson, R., et al. (2006). Heterotrophic Archaea dominate sedimentary subsurface ecosystems off Peru. Proc. Natl. Acad. Sci. U.S.A. 103, 3846-3851. doi: 10.1073/pnas.0600035103

Boyd, E. S., Pearson, A., Pi, Y., Li, W.-J., Zhang, Y. G., He, L., et al. (2011). Temperature and $\mathrm{pH}$ controls on glycerol dibiphytanyl glycerol tetraether lipid composition in the hyperthermophilic crenarchaeon Acidilobus sulfurireducens. Extremophiles 15, 59-65. doi: 10.1007/s00792-010-0339-y

Chen, A., and Poulter, C. D. (1994). Isolation and characterization of idsA: the gene for the short chain isoprenyl diphosphate synthase from Methanobacterium thetmoautotrophicum. Arch. Biochem. Biophys. 314, 339-404. doi: 10.1006/abbi.1994.1459

Elling, F. J., Könneke, M., Lipp, J. S., Becker, K. W., Gagen, E. J., and Hinrichs, K.-U. (2014). Effects of growth phase on the membrane lipid composition of the thaumarchaeon Nitrosopumilus maritimus and their implications for archaeal lipid distributions in the marine environment. Geochim. Cosmochim. Acta 141, 579-597. doi: 10.1016/j.gca.2014.07.005

Evans, J. N., Tolman, C. J., Kanodia, S., and Roberts, M. F. (1985). 2,3cyclopyrophosphoglycerate in methanogens: evidence by 13C NMR spectroscopy for a role in carbohydrate metabolism. Biochemistry 24, 5693-5698. doi: 10.1021/bi00342a001

Gagen, E. J., Huber, H., Meador, T. B., Hinrichs, K.-U., and Thomm, M. (2013). Novel cultivation-based approach to understanding the miscellaneous crenarchaeotic group (MCG) archaea from sedimentary ecosystems. Appl. Environ. Microbiol. 79, 6400-6406. doi: 10.1128/AEM.02153-13

Gliozzi, A., Relini, A., and Chong, P. L. (2002). Structure and permeability properties of biomimetic membranes of bolaform archaeal tetraether lipids. J. Memb. Sci. 206, 131-147. doi: 10.1016/S0376-7388(01)00771-2

Hartley, M. D., and Imperiali, B. (2012). At the membrane frontier: a prospectus on the remarkable evolutionary conservation of polyprenols and polyprenylphosphates. Arch. Biochem. Biophys. 517, 83-97. doi: 10.1016/j.abb.2011.10.018

Hartmann, E., and König, H. (1990). Comparison of the biosynthesis of the methanobacterial pseudomurein and the eubacterial murein. Naturwissenschaften 77, 472-475. doi: 10.1007/BF01135923

Hinz, H. J., Kuttenreich, H., Meyer, R., Renner, M., Frund, R., Koynova, R., et al. (1991). Stereochemistry and size of sugar head groups determine structure and phase behavior of glycolipid membranes: densitometric, calorimetric, and X-ray studies. Biochemistry 30, 5125-5138. doi: 10.1021/bi00235a003

Hölzl, G., and Dörmann, P. (2007). Structure and function of glycoglycerolipids in plants and bacteria. Prog. Lipid Res. 46, 225-243. doi: 10.1016/j.plipres.2007.05.001

Jones, M. B., Rosenberg, J. N., Betenbaugh, M. J., and Krag, S. S. (2009). Structure and synthesis of polyisoprenoids used in N-glycosylation across the three domains of life. Biochim. Biophys. Acta 1790, 485-494. doi: 10.1016/j.bbagen.2009.03.030

Kandler, O., and König, H. (1998). Cell wall polymers in Archaea (Archaebacteria). Cell. Mol. Life Sci. 54, 305-308. doi: 10.1007/s000180050156

Kato, S., Kosaka, T., and Watanabe, K. (2008). Comparative transcriptome analysis of responses of Methanothermobacter thermautotrophicus to different environmental stimuli. Environ. Microbiol. 10, 893-905. doi: 10.1111/j.1462-2920.2007.01508.x

Knappy, C. S., Chong, J. P. J., and Keely, B. J. (2009). Rapid discrimination of Archaeal tetraether lipid cores by liquid chromatography-tandem mass spectrometry. J. Am. Soc. Mass Spectrom. 20, 51-59. doi: 10.1016/j.jasms.2008.09.015

Kramer, J. K. G., and Sauer, F. D. (1991). Changes in the diether-to-tetraetherlipid ratio during cell growth in Methanobacterium thermoautotrophicum. FEMS Microbiol. Lett. 83, 45-50. doi: 10.1111/j.1574-6968.1991.tb04386.x

Kramer, J. K. G., Sauer, F. D., and Blackwell, B. A. (1987). Structure of two new aminophospholipids from Methanobacterium thermoautotrophicum. Biochem. J. 245, 139-143.

Kramer, J. K. G., Sauer, F. D., and Bundle, D. R. (1988). The presence of tightly bound $\mathrm{Na}+$ or $\mathrm{K}+$ in glycolipids of Methanobacterium thermoautotrophicum. Biochim. Biophys. Acta 961, 285-292. doi: 10.1016/0005-2760(88)90075-6

Krueger, R. D., Seely, R. J., and Fahrney, D. E. (1986). Intracellular K ${ }^{+}$and cyclic diphosphoglycerate pools and transients in Methanobacterium thermoautotrophicum. System. Appl. Microbiol. 7, 388-392. doi: 10.1016/S0723-2020(86)80039-X

Lai, D., Springstead, J. R., and Monbouquette, H. G. (2008). Effect of growth temperature on ether lipid biochemistry in Archaeoglobus fulgidus. Extremophiles 12, 271-278. doi: 10.1007/s00792-007-0126-6
Lechner, J., Wieland, F., and Sumper, M. (1985). Biosynthesis of sulfated saccharides $\mathrm{N}$-glycosidically linked to the protein via glucose. J. Biol. Chem. 260, 860-866.

Lipp, J. S., Morono, Y., Inagaki, F., and Hinrichs, K.-U. (2008). Significant contribution of Archaea to extant biomass in marine subsurface sediments. Nature 454, 991-994. doi: 10.1038/nature07174

Liu, X.-L., Lipp, J. S., Schröder, J. M., Summons, R. E., and Hinrichs, K.-U. (2012). Isoprenoid glycerol dialkanol diethers: a series of novel archaeal lipids in marine sediments. Org. Geochem. 43, 50-55. doi: 10.1016/j.orggeochem.2011.11.002

Matsuno, Y., Sugai, A., Higashibata, H., Fukuda, W., Ueda, K., Uda, I., et al. (2009). Effect of growth temperature and growth phase on the lipid composition of the archaeal membrane from Thermococcus kodakaraensis. Biosci. Biotechnol. Biochem. 73, 104-108. doi: 10.1271/bbb.80520

Meador, T. B., Gagen, E. J., Loscar, M. E., Goldhammer, T., Yoshinaga, M. Y., Wendt, J., et al. (2014). Thermococcus kodakarensis modulates its polar membrane lipids and elemental composition according to growth stage and phosphate availability. Front. Microbiol. 5:10. doi: 10.3389/fmicb.2014.00010

Morii, H., Eguchi, T., and Koga, Y. (2007). In vitro biosynthesis of ether-type glycolipids in the methanoarchaeon Methanothermobacter thermautotrophicus. J. Bacteriol. 189, 4053-4061. doi: 10.1128/JB.01875-06

Morii, H., and Koga, Y. (1993). Tetraether type polar lipids increase after logarithmic growth phase of Methanobacterium thermoautotrophicum in compensation for the decrease of diether lipids. FEMS Microbiol. Lett. 109, 283-288. doi: 10.1111/j.1574-6968.1993.tb06182.x

Morii, H., and Koga, Y. (1994). Asymmetric topology of diether and tetraether type polar lipids in the membrane of Methanobacterium thermoautotrophicum cells. J. Biol. Chem. 269, 10492-10497.

Nakamura, K., Terada, T., Sekiguchi, Y., Shinzato, N., Meng, X. Y., Enoki, M., et al. (2006). Application of pseudomurein endoisopeptidase to fluorescence in situ hybridization of methanogens within the family Methanobacteriaceae. Appl. Environ. Microbiol. 72, 6907-6913. doi: 10.1128/AEM.01499-06

Nemoto, N., Shida, Y., Shimada, H., Oshima, T., and Yamagishi, A. (2003). Characterization of the precursor of tetraether lipid biosynthesis in the thermoacidophilic archaeon Thermoplasma acidophilum. Extremophiles 7, 235-243.

Nicolaus, B., Trincone, A., De Rosa, M., Grant, W. D., and Gambacorta, A. (1989). Glycine betaine and polar lipid composition in halophilic archaebacteria in response to growth in different salt concentrations. FEMS Microbiol. Lett. 59, 157-160. doi: 10.1111/j.1574-6968.1989.tb03101.x

Nishihara, M., Morii, H., and Koga, Y. (1987). Structure determination of a quartet of novel tetraether lipids from Methanobacterium thermoautotrophicum. J. Biochem. 101, 1007-1015.

Nishihara, M., Morii, H., and Koga, Y. (1989). Heptads of polar ether lipids of an archaebacterium, Methanobacterium thermoautotrophicum: structure and biosynthetic relationship. Biochemistry 28, 95-102. doi: 10.1021/bi00427a014

Patel, G. B., Agnew, B. J., Jarrell, H. C., and Sprott, G. D. (1999). Stability of liposomes prepared from the total polar lipids of Methanosarcina mazei is affected by specific salt from of the lipids. J. Liposome Res. 9, 229-245. doi: 10.3109/08982109909024787

Poorter, L. M. I., Geerts, W. G., Theuvenet, A. P. R., and Keltjens, J. T. (2003). Bioenergetics of the formyl-methanofuran dehydrogenase and heterodisulfide reductase reactions in Methanothermobacter thermautotrophicus. Eur. J. Biochem. 270, 66-75. doi: 10.1046/j.1432-1033.2003.03362.x

Reeves, E. P., Yoshinaga, M. Y., Pjevac, P., Goldenstein, N. I., Peplies, J., Meyerdierks, A., et al. (2014). Microbial lipids reveal carbon assimilation patterns on hydrothermal sulfide chimneys. Environ. Microbiol. 16, 3515-3532. doi: $10.1111 / 1462-2920.12525$

Rossel, P. E., Elvert, M., Ramette, A., Boetius, A., and Hinrichs, K.-U. (2011). Factors controlling the distribution of anaerobic methanotrophic communities in marine environments: evidence from intact polar membrane lipids. Geochim. Cosmochim. Acta 75, 164-184. doi: 10.1016/j.gca.2010.09.031

Schönheit, P., Beimborn, D. B., and Perski, H.-J. (1984). Potassium accumulation in growing Methanobacterium thermoautotrophicum and its relation to the electrochemical proton gradient. Arch. Microbiol. 140, 247-251. doi: 10.1007/BF00454936

Schubotz, F., Lipp, J. S., Elvert, M., and Hinrichs, K.-U. (2011). Stable carbon isotopic compositions of intact polar lipids reveal complex carbon flow patterns among hydrocarbon degrading microbial communities at the Chapopote asphalt volcano. Geochim. Cosmochim. Acta 75, 4399-4415. doi: 10.1016/j.gca.2011.05.018 
Schubotz, F., Meyer-Dombard, D. R., Bradley, A. S., Fredericks, H. F., Hinrichs, K.-U., Shock, E. L., et al. (2013). Spatial and temporal variability of biomarkers and microbial diversity reveal metabolic and community flexibility in Streamer Biofilm Communities in the Lower Geyser Basin, Yellowstone National Park. Geobiology 11, 549-569. doi: 10.1111/gbi.12051

Seely, R. J., and Fahrney, D. E. (1983). A novel diphospho-P,P'-diester from Methanobacterium thermoautotrophicum. J. BioI. Chem. 258, 10835-10838.

Seely, R. J., and Fahrney, D. E. (1984). Levels of cyclic-2,3-diphsphoglycerate in Methanobacterium thermoautotrophicum during phosphate limitation. J. Bact 160, 50-54.

Shimada, H., Nemoto, N., Shida, Y., Oshima, T., and Yamagishi, A. (2008). Effects of $\mathrm{pH}$ and temperature on the composition of polar lipids in Thermoplasma acidophilum HO-62. J. Bacteriol. 190, 5404-5411. doi: 10.1128/JB.00415-08

Simon, M., and Azam, F. (1989). Protein content and protein synthesis rates of planktonic marine bacteria. Mar. Ecol. Prog. Ser. 51, 201-203. doi: 10.3354/meps051201

Sturt, H., Summons, R., Smith, K., Elvert, M., and Hinrichs, K.-U. (2004) Intact polar membrane lipids in prokaryotes and sediments deciphered by highperformance liquid chromatography/electrospray ionization multistage mass spectrometry - new biomarkers for biogeochemistry and microbial ecology. Rapid Commun. Mass Spectrom. 18, 617-628. doi: 10.1002/rcm.1378

Swiezewska, E., and Danikiewicz, W. (2005). Polyisoprenoids: structure, biosynthesis, and function. Prog. Lipid Res. 44, 235-258. doi: 10.1016/j.plipres.2005.05.002

Uda, I., Sugai, A., Itoh, Y. H., and Itoh, T. (2001). Variation in molecular species of polar lipids from Thermoplasma acidophilum depends on growth temperature. Lipids 36, 103-105. doi: 10.1007/s11745-001-0914-2

Uda, I., Sugai, A., Itoh, Y. H., and Itoh, T. (2004). Variation in molecular species of core lipids from the order Thermoplasmales strains depends on the growth temperature. J. Oleo. Sci. 53, 399-404. doi: 10.5650/jos.53.399

Valentine, D. L. (2007). Adaptations to energy stress dictate the ecology and evolution of the Archaea. Nat. Rev. Microbiol. 5, 316-323. doi: 10.1038/nrmicrol619

Wikström, M., Xie, J., Bogdanov, M., Mileyovskaya, E., Heacock, P., Wieslander, $\AA$., et al. (2004). Monoglucosyldiacylglycerol, a foreign lipid, can substitute for phosphatidylethanolamine in essential membrane-associated functions in Escherichia coli. J. Biol. Chem. 279, 10484-10493. doi: 10.1074/jbc.M310183200

Wörmer, L., Lipp, J., Schröder, J., and Hinrichs, K.-U. (2013). Application of two new LC-ESI-MS methods for improved detection of intact polar lipids (IPLs) in environmental samples. Org. Geochem. 59, 10-21. doi: 10.1016/j.orggeochem.2013.03.004
Yoshinaga, M. Y., Kellermann, M. Y., Rossel, P. E., Schubotz, F., Lipp, J. S., and Hinrichs, K.-U. (2011). Systematic fragmentation patterns of archaeal intact polar lipids by high-performance liquid chromatography/electrospray ionization iontrap mass spectrometry. Rapid Commun. Mass Spectrom. 25, 3563-3574. doi: $10.1002 / \mathrm{rcm} .5251$

Zavaleta-Pastor, M., Sohlenkamp, C., Gao, J. L., Zaheer, R., Fina, T. M., Raetz, C. R., et al. (2010). Sinorhizobium meliloti phospholipase C required for lipid remodeling during phosphorus limitation. Proc. Natl. Acad. Sci. U.S.A. 107, 302-307. doi: 10.1073/pnas.0912930107

Zhang, Y.-M., and Rock, C. O. (2008). Membrane lipid homeostasis in bacteria. Nat. Rev. Microbiol. 6, 222-233. doi: 10.1038/nrmicro1839

Zhu, C., Lipp, J. S., Wörmer, L., Becker, K. W., Schröder, J., and Hinrichs, K.-U. (2013). Comprehensive glycerol ether lipid fingerprints through a novel reversed phase liquid chromatography-mass spectrometry protocol. Org. Geochem. 65, 53-62. doi: 10.1016/j.orggeochem.2013.09.012

Zhu, C., Yoshinaga, M. Y., Peters, C. A., Liu, X.-L., Elvert, M., and Hinrichs, K.-U. (2014). Identification and significance of unsaturated archaeal tetraether lipids in marine sediments. Rapid Commun. Mass Spectrom. 28, 1144-1152. doi: $10.1002 / \mathrm{rcm} .6887$

Conflict of Interest Statement: The authors declare that the research was conducted in the absence of any commercial or financial relationships that could be construed as a potential conflict of interest.

Received: 09 November 2014; accepted: 04 January 2015; published online: 22 January 2015.

Citation: Yoshinaga MY, Gagen EJ, Wörmer L, Broda NK, Meador TB, Wendt J, Thomm $M$ and Hinrichs K-U (2015) Methanothermobacter thermautotrophicus modulates its membrane lipids in response to hydrogen and nutrient availability. Front. Microbiol. 6:5. doi: 10.3389/fmicb.2015.00005

This article was submitted to Extreme Microbiology, a section of the journal Frontiers in Microbiology.

Copyright (C) 2015 Yoshinaga, Gagen, Wörmer, Broda, Meador, Wendt, Thomm and Hinrichs. This is an open-access article distributed under the terms of the Creative Commons Attribution License (CC BY). The use, distribution or reproduction in other forums is permitted, provided the original author(s) or licensor are credited and that the original publication in this journal is cited, in accordance with accepted academic practice. No use, distribution or reproduction is permitted which does not comply with these terms. 